\title{
Geoengineering and geographers: Rewriting the Earth in what image?
}

DOI:

10.1111/area.12495

\section{Document Version}

Accepted author manuscript

Link to publication record in Manchester Research Explorer

\section{Citation for published version (APA):}

Bellamy, R., \& Palmer, J. (2018). Geoengineering and geographers: Rewriting the Earth in what image? Area. https://doi.org/10.1111/area.12495

\section{Published in:}

Area

\section{Citing this paper}

Please note that where the full-text provided on Manchester Research Explorer is the Author Accepted Manuscript or Proof version this may differ from the final Published version. If citing, it is advised that you check and use the publisher's definitive version.

\section{General rights}

Copyright and moral rights for the publications made accessible in the Research Explorer are retained by the authors and/or other copyright owners and it is a condition of accessing publications that users recognise and abide by the legal requirements associated with these rights.

\section{Takedown policy}

If you believe that this document breaches copyright please refer to the University of Manchester's Takedown Procedures [http://man.ac.uk/04Y6Bo] or contact uml.scholarlycommunications@manchester.ac.uk providing relevant details, so we can investigate your claim.

\section{OPEN ACCESS}




\title{
Geoengineering and geographers: Rewriting the Earth in what image?
}

\author{
Rob Bellamy ${ }^{a, b^{*}}$ and James Palmer ${ }^{a, c}$ \\ a Institute for Science, Innovation and Society, University of Oxford, 64 Banbury Road, Oxford, OX2 \\ $6 \mathrm{PN}$, United Kingdom \\ ${ }^{\mathrm{b}}$ Department of Geography, University of Manchester, Oxford Road, Manchester, M13 9PL, United \\ Kingdom \\ ${ }^{c}$ School of Geographical Sciences, University of Bristol, University Road, Bristol, BS8 1SS, United \\ Kingdom \\ * Corresponding author: rob.bellamy@manchester.ac.uk
}

\begin{abstract}
Large-scale intervention in the Earth's climate system features centrally both in definitions of, and proposed responses to, the Anthropocene. In its deliberate guise-as climate geoengineering-such intervention is highly contentious, threatening to profoundly reshape the geography and politics of environmental governance frameworks, not to mention the nature of the environments towards which those frameworks are oriented. Yet, even as experiments with geoengineering technologies are growing in number, geographers continue to engage seldom with scientific, political or indeed public debates about them. In this paper we contend that geographical ideas about space, scale, power and geopolitics must urgently be brought to bear on ongoing efforts to experiment with geoengineering, and to deliberate its future role in responses to climate change. We develop this argument in two parts. First, we suggest that ongoing debates about the acceptability of geoengineering experimentation would benefit from recognising incumbent spatial and scalar categorisations (e.g. small-scale vs. large-scale, indoors vs. outdoors) not as fixed ontological anchors, but as relational and provisional constructs, open to being rethought in new, potentially productive ways. Second, we call for geographers to document and contest inequalities and injustices, both in debates about what geoengineering is or might become, and in the outcomes generated by efforts to undertake geoengineering in practice. Here there are opportunities for geographers to reshape the frames of reference used by others to comprehend the implications of the Anthropocene itself, drawing on traditional disciplinary strengths in ecofeminism, political ecology and environmental justice, as well as the production of space and critical geopolitics. Such endeavours, we contend, will form a vital complement to existing geographical engagements with the concept of the Anthropocene, reaffirming the value of the discipline's distinctive-and explicitly normative-voice within ongoing policy and public deliberations.
\end{abstract}

Keywords: Anthropocene, Climate Geoengineering, Experimental Space, Environmental Justice, Geopolitics, Production of Space

\section{Introduction: Geoengineering and Geographical Thought}

Experiments with geoengineering technologies-prospective large-scale interventions in the Earth's climate system that seek to either remove greenhouse gases from the atmosphere or reflect sunlight 
back into space-are growing in number. According to the IPCC, if the Paris Agreement's ambition to limit global warming to no more than $1.5^{\circ} \mathrm{C}$ above preindustrial levels is to be met, the widespread deployment of some form of 'geoengineering' is highly likely to be necessary (van Vuuren et al., 2017). The very idea of this engineer-able Earth, or 'geoengine' (Yusoff, 2013), invites critical scrutiny of the ontological commitments underpinning geoengineering experiments and agendas. Yet human geographers continue to engage only seldom with scientific, political or indeed public debates about these technologies, tending to leave the way clear for other voices to shape their role in human responses to climate change, and in comprehending the implications of the Anthropocene more broadly.

Several of those geoengineering experiments which have taken place have attracted a great degree of public interest and controversy (see, for example, Stilgoe, 2015), and-with more experiments planned -this is only likely to intensify. While some studies across nation states have shown that public perceptions of geoengineering can be similar (Wibeck et al., 2017; Carr \& Yung, 2018), a growing body of research is illuminating the importance of situated knowledge (Hulme, 2008), contextual framings (Bellamy et al., 2012), deliberative spaces (Bellamy et al., 2017), particular places (Buck, 2018a) and local meanings (Gannon \& Hulme, 2018), in shaping perceptions of the various technologies. Geographical context is also crucial, moreover, to the form and substance of emerging guidelines and incentives for responsible geoengineering research and development in different contexts (Bellamy, 2018; Buck, 2018b).

As experiments with various geoengineering technologies continue, it is vital that closer attention be paid to the ways in which geoengineering, as a "material-discursive practice" (Yusoff, 2013: 2799), is serving to reshape space, scale, power, and indeed geopolitics. For example, a geographical approach to space-as fundamentally relational-would recognise from the outset the mutual constitution of imaginaries of geoengineering, and the heterogeneous spatial contexts within which they emerge and in turn serve to make themselves felt. And, following Clark (2013: 2828), we might expect new modes of geopolitics - 'geologic politics' - to emerge in the coming years and decades, as geoengineering begins to forge new kinds of relations between the "human aspects of place making" and "larger scale earth processes".

Rather than take any such relational view, however, would-be geoengineers and those who would seek to govern them routinely use spatial and scalar concepts in a strictly fixed, physical sense.

Different 'types' of space or 'levels' of scale, for example, are understood to carry with them innate, pre-given levels of risk which lend themselves à priori to different ordinal classes of experiment. Ambitions to perform geoengineering 'field' experiments, for example, are often moderated by their being of a 'small-scale' (e.g. Parson \& Keith, 2013; Dykema et al., 2014; Long et al., 2015), even as numerous 'small-scale', 'limited' experiments have ended in controversy (e.g. Schiermeier, 2009; Tollefson, 2012; Stilgoe, 2015). What is overlooked here is the inevitable contestability of "what is to be defined as small-scale and how the limits of the experiment are to be conceived if the experiment is in the world" (Yusoff, 2013: 2804, emphasis added).

There is therefore a clear imperative to turn the gaze of relational geography onto the ways in which geoengineering experiments are spatially classified, and the ways geoengineering is imagined more broadly. In the first part of this paper, we draw on research examining public perceptions of geoengineering research in a range of contexts to contend that classifications of experimental space should always be apprehended as provisional and open-ended, rather than fixed and pre-given. While this perspective implies that the spatial imprint of geoengineering experimentation and indeed governance can always inscribed differently, however, it does not ask how the authority to kickstart or participate in this rewriting process might be acquired by different groups. The second 
section of the paper therefore calls for the more intensive application by human geographers of core disciplinary concepts and tools-including those of ecofeminism, political ecology, and critical geopolitics - to an examination of power, inequality and injustice, both in participation in debates about what geoengineering is (or might yet become), and in the outcomes being generated by efforts to undertake geoengineering in practice.

\section{Relational, Open-Ended Spaces of Geoengineering Experimentation}

"We have inherited an imagination [of space] so deeply ingrained that it is often not actively thought.... It is an imagination with the implacable force of the patently obvious. That is the trouble." (Massey, 2005: 17).

The deeply ingrained spatial imagination to which Massey refers in For Space is one characterised by an often-unconscious commitment to mechanistic, Cartesian principles, grounded in ostensibly fixed and self-evident vertical and horizontal dimensions. Such understandings are clearly visible in the nested hierarchies of-and binary divisions between - the possible experimental spaces defined for geoengineering (see Table 1). The Solar Radiation Management Governance Initiative (2011), for example, proposes two categories of 'indoors activities': '1. Non-hazardous studies' and '2. Contained laboratory studies or passive observations of nature'; and three categories of 'outdoors activities': '3. Small field trials'; '4. Medium and large-scale field trials'; and '5. Deployment activities' (see Keith [2013] and Keith et al. [2014] for further examples). These spatial classifications are deemed to constitute an apolitical and objective means of adjudicating between experiments that carry more or less physical risk. Consequently, they are often used as proxies for delimiting forms of geoengineering experimentation that are more or less publicly acceptable.

Table 1. Examples of conflated vertical and horizontal spatial binaries for the acceptability of geoengineering experiments

Small-scale

Microscale

Research

Contained

Laboratory studies

Indoors activities

\author{
Large-scale \\ Global \\ Deployment \\ Uncontained \\ Field trials \\ Outdoors activities
}

Yet, as we know from geoengineering experiments that have already taken place, those that are ostensibly small-scale or 'limited' in some way can still end in controversy. The key reason for this, we argue, is that these spatial classifications are in fact much more fluid, emergent and contestable than they appear. A more relational approach would apprehend experimental spaces as the product of interrelations between multiplicities, or the "contemporaneous existence of a plurality of trajectories" (Massey, 2005: 12). Spaces of geoengineering experimentation, in short, will always be qualified and modulated through broader concerns about the politics, ethics and epistemological commitments of scientific work in this area. Such an approach "puts into question what might be the pertinent lines of differentiation in any particular situation" (ibid: 12). Indeed, recent research into public perceptions of geoengineering experiments and their governance has begun to open up the 
diverse potential of those 'lines of differentiation'. Bellamy et al. (2017), for instance, identify four such lines: the level of containment; uncertainty around what the outcomes would be; the reversibility of any impacts; and the scientific 'purity' of the research. Drawing on this framework, we seek to explicate these multiplicities by illustrating some of the alternative spatial imaginaries that abound in public discourses on geoengineering experimentation.

The first multiplicity, and that which is most reminiscent of the Cartesian imagination, is the degree to which geoengineering experiments are believed to be contained. In extant governance propositions, this often takes the form of whether or not an experiment is conducted indoors. Yet publics have productively engaged with the notion of containment in different ways, and with different implications for governance. One such differentiation concerns the idiom of 'naturalness', which has proven to be a powerful determinant of geoengineering acceptance, for instance among geographically varied citizens in the UK (Corner et al., 2013). Technologies that are perceived to be more 'natural' have been understood to be better "balanced" and "self-contained" than those that are not. Under this view, 'natural' experiments performed outdoors may be just as acceptable as those that are performed indoors. The encapsulation of an experiment-whether or not it would release foreign materials into the environment-is another perspective on more 'modular' containment. Those real-world experiments that would release materials, such as for ocean iron fertilisation, have been seen as unacceptable, particularly among those whose territories are directly affected (Gannon \& Hulme, 2018).

The second multiplicity is the degree to which geoengineering experiments are believed to be uncertain. Geoengineering has been characterised as an archetypal example of a governance issue demanding 'post-normal' science; that is to say, as well as being an issue of high stakes, it is one of great systems uncertainties (Funtowicz \& Ravetz, 1993). The straightforward scientific response has been that uncertainty is enabling: carrying out experiments will be the only way to reduce those uncertainties and provide decision makers with the information they need to govern. Yet, the 'extended peer community' of publics that are necessitated in the scrutiny of post-normal science have conceptualised uncertainty in markedly different ways. The starkest departure from seeing uncertainty as an enabling device has been in the attention given to unintended impacts that could arise from geoengineering experiments. Here, uncertainty can be seen as a reason to constrain research, for example as has been found among Swedish citizens (Wibeck et al., 2015). Another sort of incertitude, ambiguity, may also exist at the level of the social framing of experiments, where contending criteria for 'success' may enable or constrain research ex ante or ex post (Bellamy et al., 2016). Experiments have also been seen to have a constitutive relationship with uncertainty, whereby in order to observe the true effectiveness of geoengineering scientists would have to undertake global experiments tantamount to deployment. This view of uncertainty has been mobilised to call for an end to research into stratospheric aerosol injection altogether (Hulme, 2014).

The third multiplicity is the degree the impacts of a geoengineering experiment are believed to be reversible. This, and the corresponding need to minimise such impacts, has been shown to be a very common concern among publics who have been engaged with geoengineering, including those in the UK and Japan (Pidgeon et al., 2013; Asayama et al., 2017). And yet, reversibility can be fruitfully differentiated in other ways. Under the view that experiments might contribute to "reversing the messing that we've already done", publics have instead expressed an interest in the need to maximise impacts (Corner et al., 2013: 944). Focus on the perceived need to reverse the impacts of geoengineering technologies or their ability to reverse the impacts of climate change, however, fixates on the destination of experiments at the expense of the journey. German citizens have also expressed concerns about a 'slippery slope' from research to deployment (Merk et al., 2015). Under 
this view, governance might focus on slowing the pace of experimentation (Pidgeon et al., 2013). Publics may also possess different concerns about how experiments might change the political landscape within which geoengineering technologies reside: how would one 'reverse' the social and discursive impacts of an experiment that appeared to provide strong (or, conversely, weak) evidence of the ability of a geoengineering technology to remove carbon dioxide from the atmosphere, for example? Once such evidence is brought into being, debates about geoengineering cannot go back to their previous states, and this in turn will make some kinds of future developments or pathwaysin both scientific and political settings-more (or less) likely.

The fourth multiplicity is the degree to which a geoengineering experiment could be thought of as scientifically 'pure' and free from private interests. The Oxford Principles for governing geoengineering have declared that "the involvement of the private sector in the delivery of a geoengineering technique should not be prohibited, and may indeed be encouraged to ensure that deployment of a suitable technique can be effected in a timely and efficient manner" (Rayner et al., 2013: 502). Yet, these specialist-defined principles might have evolved differently had the wider public been involved in their definition from the outset. Indeed, publics can exhibit quite different perspectives on private involvement, with some taking the view that the private sector should not be involved at all, for example in Japan (Asayama et al., 2017). Similar sentiments extend in other cases to the notion of maverick or 'rogue' scientists who might operate outside the bounds of accepted codes of ethics and practice. This was shown to be particularly the case with residents of the Haida Gwaii archipelago, who in 2012 were subject to 120 tonnes of iron sulphate being released into their waters as part of an ocean fertilisation experiment (Gannon \& Hulme, 2018).

The nuanced understandings of geoengineering experiments exhibited by publics expose how Cartesian approaches to space are underpinned by misleading binaries. The containment multiplicity, for instance, shows how place-based dualisms (contained-uncontained, laboratory studies-field trials and indoors-outdoors) are complicated by fluid, emergent and contested understandings: 'contained' means indoors to some, but equally, it meant natural or encapsulated to others. Similarly, the uncertainty multiplicity shows how the scale-based dualisms (small-scalelarge-scale, microscale-global and research-deployment) are complicated by relational understandings: a lack of knowledge could legitimately be used to justify both enabling and constraining experiments at the same scales and places while the constitution of uncertainty by certain experiments means that research and deployment would become one and the same. Thus, small-scale experiments that are relatively limited in extent, like the Stratospheric Particle Injection for Climate Engineering (SPICE) project testbed and the Loha Fertilisation Experiment (LOHAFEX), for example, would not likely be acceptable if they raised, for instance, concerns about private interests and physical encapsulation (which, in point of fact, they did, respectively [see Stilgoe, 2015; Schiermeier, 2009]). The same applies to similarly spatially framed experiments, like the forthcoming Stratospheric Controlled Perturbation Experiment (SCoPEx) (see Dykema et al., 2014).

\section{New Geographies of Geoengineering: Inequality, The Production of Space, Geopolitics}

"[I]t is a world being made, through relations, and there lies the politics" (Massey, 2005: 15)

Geographical ideas have implications not only for rethinking the spatiality of geoengineering experimentation, but also for broader societal and policy-making debates about the role geoengineering technologies might play in future responses to anthropogenic climate change. Policy 
deliberations about geoengineering in the global North, at least to date, have tended to privilege knowledge with universalising or 'globalising instincts' (Hulme, 2010). Ongoing political discussions about the potential role of carbon dioxide removal in future European Union climate policy, for example, are heavily informed by global emissions trajectories and scenarios produced by the international community of climate scientists (Geden et al., 2018). And at the level of specific geoengineering technologies, assessments of technical and economic feasibility tend to isolate specific innovations from the messy, situated socio-economic and political contexts within which they are developed and deliberated (see for example Keith et al.'s [2018] recent assessment of the feasibility of direct air capture).

As Hulme (2010: 559) points out in respect of environmental problems more broadly, forms of knowledge which "assert themselves as the unassailable view from everywhere... lend support to managerial instincts that seek to centralise political power and social control." It is no coincidence, therefore, that burgeoning aspirations towards the 'planetary modification' of what Yusoff (2013) provocatively terms the Earth's 'geoengine' can be traced to restricted spaces of elite scientific and political deliberation, and that these spaces are largely devoid of public participation. Against these tendencies, geographical analyses can highlight the ways in which purportedly universal forms of knowledge undergo "constant reinterpretation... in different spatial contexts" (Hulme, 2008: 6) -or 'spaces of speech' (Livingstone, 2007)-about geoengineering. And, no less importantly, geographers can also document how practices of knowledge production and representation, both scientific and vernacular, are always mutually intertwined with processes by which power and authority are allocated in efforts to govern a putative, 'geoengineered' future (Anderson, 2010).

An obvious starting point in this regard concerns the nature of the voices and perspectives which get to be heard-or not-in debates about geoengineering. The heavy influence of technical, scientific assessments of geoengineering technologies, and particularly of climate modelling outputs in identifying probable emissions trajectories, has already been noted, but there are other axes of inclusion and exclusion towards which geographical scrutiny might productively be directed. Buck et al. (2013), for instance, have recently sought to open up discussions of the gendered dimensions of geoengineering, noting the restricted demographics of those currently pushing the geoengineering agenda, the prevalence of masculinist ideals in the design of specific technologies, the persistence of narratives legitimising man's domination over nature, as well as potentially disproportionate social impacts for women and other marginalised groups.

Some of these inequalities in participation (and indeed outcomes) might be countered by engaging directly with communities and groups not normally regarded as having relevant ideas or perspectives, thereby shedding light on 'civic epistemologies' of geoengineering (Jasanoff, 2007). Carr \& Yung (2018), for example, have sought to explore public perceptions of geoengineering in a range of non-Western contexts (including sub-Saharan Africa and the South Pacific), while others have engaged with citizens in diverse settings in the global North, including in Finnish Lapland (Buck, 2018a), Haida Gwaii (Gannon \& Hulme, 2018), Japan (Asayama et al., 2017), New Zealand, Sweden and the US (Wibeck et al,, 2017). Geographers have much to contribute to these emerging strands of enquiry, drawing not just on the tools of ecofeminist critique, political ecology and environmental justice, but also on unique disciplinary approaches to the concept of place itself. Specifically, geographers can help to counter dominant views of place as a passive, static backdrop for experimentation with novel techno-scientific 'solutions' to a consensually-established climate 'emergency'. Instead, they might promote an 'interpretivist' view in which competing imaginaries, discourses and narratives around geoengineering strive to establish compelling connections between the past and the future in inextricably local, situated contexts (Anderson, 2010; 
MacGillivray \& Franklin, 2015). Through deploying participatory and co-productionist research methods in these settings, moreover, geographers can also help to contribute to the realisation of "self-determined planning for climate change" (Whyte, 2017: 154) in which developing countries take a leading role in discussions about the ethics and governance of geoengineering (Atiq Rahman et al., 2018, Winickoff et al., 2015).

Beyond highlighting and counteracting structural inequalities and injustices, geographers are also well-placed to highlight the role of geoengineering in bringing into being new imaginaries and orderings of space itself. Geoengineering here is a fluid material-discursive object that is always inthe-making in ways that vary across space, but that act of making goes beyond researching, developing and fine-tuning discrete technological innovations, to encompass the active reconstitution of the spatial logics by which "efforts to regulate environments and to regulate human conduct" (Mahony \& Endfield, 2018: 12) are ordered and intertwined. To take one possible example, deploying bioenergy with carbon capture and storage (BECCS) on a large scale could serve to bring into being an increasingly 'horizontal' energy system (Huber \& McCarthy, 2017), underpinned less by inorganic fossil fuels than by the photosynthetic capacities of terrestrial plants and trees. Under these circumstances, geoengineering could become a neo-colonial tool promulgating existing global inequalities in wealth and standards of living, particularly if fertile land in the subtropics and tropics is enrolled within international supply chains to help perpetuate highconsumption, energy-intensive lifestyles in the global North. Countless other forms of spatial reordering promulgated by geoengineering are of course possible, but in all cases, geographers should be at the forefront of documenting and critically interrogating the inevitable connections which are being forged between those spatial articulations, and the historically uneven geographies of capitalism and colonialism which have persistently undergirded "humanity's impact on the Earth system", and as such the bringing into being of the Anthropocene itself (Barry \& Maslin, 2016: 7).

Finally, geoengineering's ability to produce new forms and orderings of space will inevitably have significant implications for the shape-and substance-of global geopolitics in the Anthropocene (Dalby, 2015). As climate change threatens to have increasingly severe impacts in places disproportionately populated by citizens of less affluent states, for instance, the deployment of carbon dioxide removal or solar radiation management technologies could come to be framed as a moral obligation on the part of affluent governments in the global North, potentially rendering countries of the global South permanently dependent upon richer nations for 'trickle down' climate geoengineering benefits. For Clark (2013: 2831), such developments would usher into being a new kind of "geologic politics" underpinned not merely by efforts by national states to territorialise and govern the Earth's surface, but by initiatives oriented towards harnessing and redirecting the "deep temporalities and elemental forcefulness" of the Earth, encompassing dynamic elements of its atmosphere and subterranean geology. The role of so-called 'inhuman' forces, and indeed the materiality of the Earth itself, in constituting this new "vertical geopolitics" (Elden, 2013), demands urgent engagement from political geographers interested in the relationships between geoengineering and the production of new social and political orders in the Anthropocene.

\section{Conclusion: Rewriting Geoengineering in Geography's Image}

Deliberations about the acceptability of geoengineering experiments have to date largely been grounded in, and constrained by, overtly Cartesian determinations of space, place and scale. The first half of this paper has argued that dominant, binary modes of spatial and scalar categorisation should not be understood as fixed or pre-given ontological anchors, but rather as fluid, emergent 
and contestable imaginaries. It further suggests that geographical thinking is essential to exposing the intertwining of these imaginaries within situated local contexts, to highlight their open-ended nature, and thus to expose their innate potential to be reshaped and reconfigured in new, potentially productive ways. Taking the fluidity and mutability of geoengineering imaginaries as its starting point, the second section of the paper then proposed three inter-related areas of inquiry for human geographers interested in questions of power, inequality and potentially injustice surrounding both the development of these imaginaries, and their potential consequences in the future.

Through an attention to the relational nature of spatial classifications we have illuminated how any effort to differentiate between different purported 'types' of experimental space will always be provisional and mutable. From this perspective, emerging legal instruments that pertain to geoengineering, such as the updated 1992 UN Convention on Biological Diversity (which allows "small scale scientific research studies that would be conducted in a controlled setting") will in all likelihood continue to be met with contestation. Moreover, the classification of 'geoengineering' itself, defined in many quarters as "the deliberate large-scale intervention in the Earth's climate system" (Royal Society, 2009: ix), will also remain contested. The existence of contrasting, and in some cases mutually contradictory spatial imaginaries in debates about geoengineering experiments reveals the intrinsic multiplicity of experimental space itself. This multiplicity, we argue, should not be seen as a source of epistemic dissonance to be closed down or disciplined into a fixed, pre-given roster of ways of experimenting. Instead, it should be recognised as a potentially generative force capable of yielding up new imaginaries of experimental space-and indeed new ethics of experimenting with the Earth's climate system-to be continually explored and left open. The task for human geographers then, is to seek to explore and better document, in both academic and public fora, how prevailing spatial imaginaries around geoengineering technologies and their implications are constituted and contested, as well as the ways in which they serve to enable particular political, ethical and epistemological commitments while precluding others.

Beyond calling for a relational view of experimental spaces, the paper has also suggested that geographical concepts and tools have a crucial role to play in interrogating questions of power, inequality and injustice around geoengineering. Specifically, we have argued that the discipline's strengths in ecofeminist analysis, political ecology and environmental justice work positions it ideally to scrutinise emergent power dynamics governing the ability of different groups and voices to participate fully in debates about what geoengineering is (and what it might become). And, while studies of public perceptions of geoengineering in different contexts are multiplying, geographical strengths in participatory, co-productionist research could yet build upon such work to help marginalised and under-represented communities and groups realise genuinely self-determined planning for climate change (Whyte, 2017). In addition to questions about participation and authority in governance processes, there are also innately geographical questions to be explored in relation to the outcomes that geoengineering might have in practice. These include the potential for geoengineering to produce new orderings and imaginaries of space itself, with potentially profound consequences for the form and substance of environmental governance regimes, but also the potential for geoengineering to bring into being new modes and logics of geopolitics centred around 'deep' temporalities and 'inhuman' geological forces (Clark, 2013).

Taken in the round, deeper geographical engagement with geoengineering could prove vital in helping to bring into focus elements of the so-called 'Anthropo-not-seen' (Lorimer, 2016), by beginning to shed light on diverse alternative imaginaries of forthcoming planetary dangers as they are being constructed in various contexts outside of elite scientific and political networks in the 
global North. And such endeavours, we contend, will form a vital complement to already-existing, diverse geographical engagements with the concept of the Anthropocene, reaffirming the value of the discipline's distinctive-and explicitly normative-voice within ongoing policy and public deliberations.

\section{References}

Anderson, B. (2010): Preemption, precaution, preparedness: Anticipatory action and future geographies. Progress in Human Geography, 36, 777 - 798.

Asayama, S., Sugiyama, M., \& Ishii, A. (2017): Ambivalent climate of opinions: Tensions and dilemmas in understanding geoengineering experimentation. Geoforum, 80, $82-92$.

Atiq Rahman, A., Artaxo, P., Asrat, A. and Parker, A. (2018): Developing countries must lead on solar geoengineering research. Nature, 556, 22-24.

Barry, A. and Maslin, M. (2016): The Politics of the Anthropocene: A Dialogue. Geo: Geography and Environment, 3(2), 1-12.

Bellamy, R. (2018): Incentivize negative emissions responsibly. Nature Energy, DOI: 10.1038/s41560018-0156-6.

Bellamy, R., Chilvers, J. Vaughan, N. and Lenton, T. (2012): A review of climate geoengineering appraisals. WIREs Climate Change, 3, $597-615$.

Bellamy, R., Chilvers, J. and Vaughan, N. (2016): Deliberative Mapping of options for tackling climate change: Citizens and specialists 'open up' appraisal of geoengineering. Public Understanding of Science, 25, $269-286$.

Bellamy, R., Lezaun, J. and Palmer, J. (2017): Public perceptions of geoengineering research governance: an experimental deliberative approach. Global Environmental Change, 45, 194 - 202.

Buck, H. (2018a): Perspectives on solar geoengineering from Finnish Lapland: Local insights on the global imaginary of Arctic geoengineering. Geoforum, 9, 78-86.

Buck, H. (2018b): The politics of negative emissions technologies and decarbonization in rural communities. Global Sustainability, 1, 1-7.

Buck, H.J., Gammon, A.R. and Preston, C.J. (2013): Gender and Geoengineering. Hypatia, 29(3), 651669.

Carr, W. and Yung, L. (2018): Perceptions of climate engineering in the South Pacific, Sub-Saharan Africa, and North American Arctic. Climatic Change, 147, 119 - 132.

Clark, N. (2013): Geoengineering and geologic politics. Environment and Planning A, 45, 2825-2832.

Corner, A., Parkhill, K., Pidgeon, N. and Vaughan, N. (2013): Messing with nature? Exploring public perceptions of geoengineering in the UK. Global Environmental Change, 23, 938 - 947.

Dalby, S. (2015): Geoengineering: The next era of geopolitics? Geography Compass, 9(4), 190-201.

Dykema, J., Keith, D., Anderson, J. and Weisenstein, D. (2014): Stratospheric controlled perturbation experiment: a small-scale experiment to improve understanding of the risks of solar geoengineering. 
Philosophical Transactions of the Royal Society A: Mathematical, Physical and Engineering Sciences, DOI: 10.1098/rsta.2014.0059.

Elden, S. (2013): Secure the volume: Vertical geopolitics and the depth of power. Political Geography, 34, 35-51.

Funtowicz, S. and Ravetz, J. (1993): Science for the post-normal age. Futures, 25, $739-755$.

Gannon, K. and Hulme, M. (2018): Geoengineering at the "Edge of the World": Exploring perceptions of ocean fertilisation through the Haida Salmon Restoration Corporation. Geo: Geography and Environment, 1-21.

Geden, O., Scott, V. and Palmer, J. (2018): Integrating carbon dioxide removal into EU climate policy: Prospects for a paradigm shift. Wiley Interdisciplinary Reviews: Climate Change, 9(4), 1-10.

Huber, M.T. and McCarthy, J. (2017): Beyond the subterranean energy regime? Fuel, land use and the production of space. Transactions of the Institute of British Geographers, 42, 655-668.

Hulme, M. (2008): Geographical work at the boundaries of climate change. Transactions of the Institute of British Geographers, 33, 5-11.

Hulme, M. (2010): Problems with making and governing global kinds of knowledge. Global Environmental Change, 20, 558-564.

Hulme, M. (2014): Can science fix climate change? A case against climate engineering. Polity: Cambridge.

Jasanoff, S. (2007): Designs on Nature: Science and Democracy in Europe and the United States. Princeton University Press, Princeton, NJ.

Keith, D. (2013): A case for climate engineering. MIT Press: Cambridge, MA.

Keith, D., Duren, R. and MacMartin, D. (2014): Field experiments on solar geoengineering: report of a workshop exploring a representative research portfolio. Philosophical Transactions of the Royal Society A: Mathematical, Physical and Engineering Sciences, DOI:10.1098/rsta.2014.0175.

Keith, D.W., Holmes, G., St. Angelo, D. and Heidel, K. (2018): A Process for Capturing $\mathrm{CO}_{2}$ from the Atmosphere. Joule, 2, 1-22.

Livingstone, D. (2007): Science, Site and Speech: Scientific Knowledge and the Spaces of Rhetoric. History of the Human Sciences, 20, $71-98$.

Long, J., Loy, F. and Morgan, G. (2015): Start research on climate engineering. Nature, 518, $29-31$.

Lorimer, J. (2017). 'The Anthropo-scence: A guide for the perplexed.' Social Studies of Science 47(1): $117-142$.

MacGillivray, B. and Franklin, A. (2015): Place as a boundary device for the sustainability sciences: Concepts of place, their value in characterising sustainability problems, and their role in fostering integrative research and action. Environmental Science and Policy, 53, $1-7$.

Mahony, M. and Endfield, G. (2018): Climate and colonialism. Wiley Interdisciplinary Reviews: Climate Change, 9(2), 1-16.

Massey, D. (2005): For space. Sage: London. 
Merk, C., Pönitzsch, G., Kniebes, C., Rehdanz, K. and Schmidt, U. (2015): Exploring public perception of stratospheric aerosol injection. Climatic Change, 130, 299-312.

Parson, E. and Keith, D. (2013): End the deadlock on governance of geoengineering research. Science, 339, $1278-1279$.

Pidgeon, N., Parkhill, K., Corner, A. and Vaughan, N. (2013): Deliberating stratospheric aero-sols for climate geoengineering and the SPICE project. Nature Climate Change, 3, 451-457.

Rayner, S., Heyward, C., Kruger, T., Pidgeon, N., Redgwell, C. and Savulescu, J. (2013): The Oxford Principles. Climatic Change, 121, 499 - 512.

Royal Society, The (2009): Geoengineering the climate: science, governance and uncertainty. The Royal Society: London.

Schiermeier, Q. (2009): Ocean fertilization experiment draws fire. Nature, DOI:10.1038/news.2009.26.

Solar Radiation Management Governance Initiative (2011): Solar Radiation Management: the governance of research.

Stilgoe, J. (2015). Experiment Earth: Responsible Innovation in Geoengineering. Routledge: Oxon.

Tollefson, J. (2012): Ocean fertilisation project off Canada sparks furore. Nature, 490, 458 - 459.

van Vuuren, D., Hof, A., Sluisveld, M. and Riahi, K. (2017): Open discussion of negative emissions is urgently needed. Nature Energy, 2, $902-904$.

Whyte, K. (2017): Indigenous Climate Change Studies: Indigenizing Futures, Decolonizing the Anthropocene. English Language Notes, 55(1-2), 153-162.

Wibeck, V., Hansson, A. and Anshelm, J. (2015): Questioning the technological fix to climate change lay sense-making of geoengineering in Sweden. Energy Research and Social Science, 7, 23 - 30.

Wibeck, V., Hansson, A., Anshelm, J., Asayama, S., Dilling, L., Feetham, P. and Hauser, R. (2017): Making sense of climate engineering: a focus group study of lay publics in four countries. Climatic Change, 145, $1-14$.

Winickoff, D., Flegal, J. and Asrat, A. (2015): Engaging the Global South on climate engineering reserch. Nature Climate Change, 5, 627-634.

Yusoff, K. (2013): The geoengine: geoengineering and the geopolitics of planetary modification. Environment and Planning A, 45, 2799-2808. 